\title{
Evaluation of the performance of the operating room by the real time of room occupancy
}

\author{
Nakhli M.S., Kahloul M., Harrathi M.A., Chakroun A., Mhamdi S. \\ Sahloul Hospital, Dept of Anaesthesiology \& Intensive Care, Sousse, Tunisia \\ Introduction:
}

The operating room is the most cost consuming area of hospitals. However, it still suffers from the problem of non-optimized organization. The aim of this study is to evaluate the performance of our operating rooms by the real room occupancy time (RROT). We will also try to identify the main causes that could alter it and to study the problem of deprogramming.

\section{Methods:}

This is an observational study conducted in two operating rooms (OR) of different fields during the month of August 2016. For the two studied rooms, a pre-established data sheet was filled during the days of scheduled activity. The collected parameters were total RROT, RROT broken down into periods, room occupancy rate, room overflow rate, incidence and causes of non-compliance with the surgical program and causes of RROT alteration.

\section{Results:}

The month of August included 23 days of scheduled activities for the two studied rooms. On average, $1.86 \pm 1.24$ acts were performed per room and per day with a total of 86 acts.

The mean start time of the activity was $41.93 \pm 16.5 \mathrm{~min} /$ day. The mean time lost per room and per day with a patient in the room was $13.54 \pm 19.7 \mathrm{~min} /$ day. The RROT was $246.56 \mathrm{~min} / \mathrm{day}$. This RROT corresponds to an average occupancy rate of $68.49 \% \pm 28.19$. The mean overflow time was $11.51 \pm 26.26 \mathrm{~min} /$ day. (Table 1, Figure 1).

Table 1: RROT broken down into periods

\begin{tabular}{lccc}
\hline & Mean \pm DS & Min & Max \\
\hline \hline The overall RROT & $246.56 \pm 101.49$ & 0 & 475 \\
Patient preparation & $23.72 \pm 10.95$ & 10 & 55 \\
Anesthesia induction & $19.27 \pm 10.64$ & 5 & 55 \\
Surgery & $140.61 \pm 67.13$ & 30 & 350 \\
Dressing & $12.84 \pm 7.095$ & 2 & 35 \\
Patient awakening & $21 \pm 10.15$ & 5 & 60 \\
Room preparation & $26.36 \pm 8.24$ & 10 & 50 \\
\hline \hline
\end{tabular}

The deprogramming rate was $30.64 \%$. Its main causes are the overshoot of the vacation time offered to surgeons $(36.84 \%)$, the emergencies (18.42\%) and the non respect of anesthesia instructions $(15.78 \%)$.

Figure 1: Causes of RROT alteration

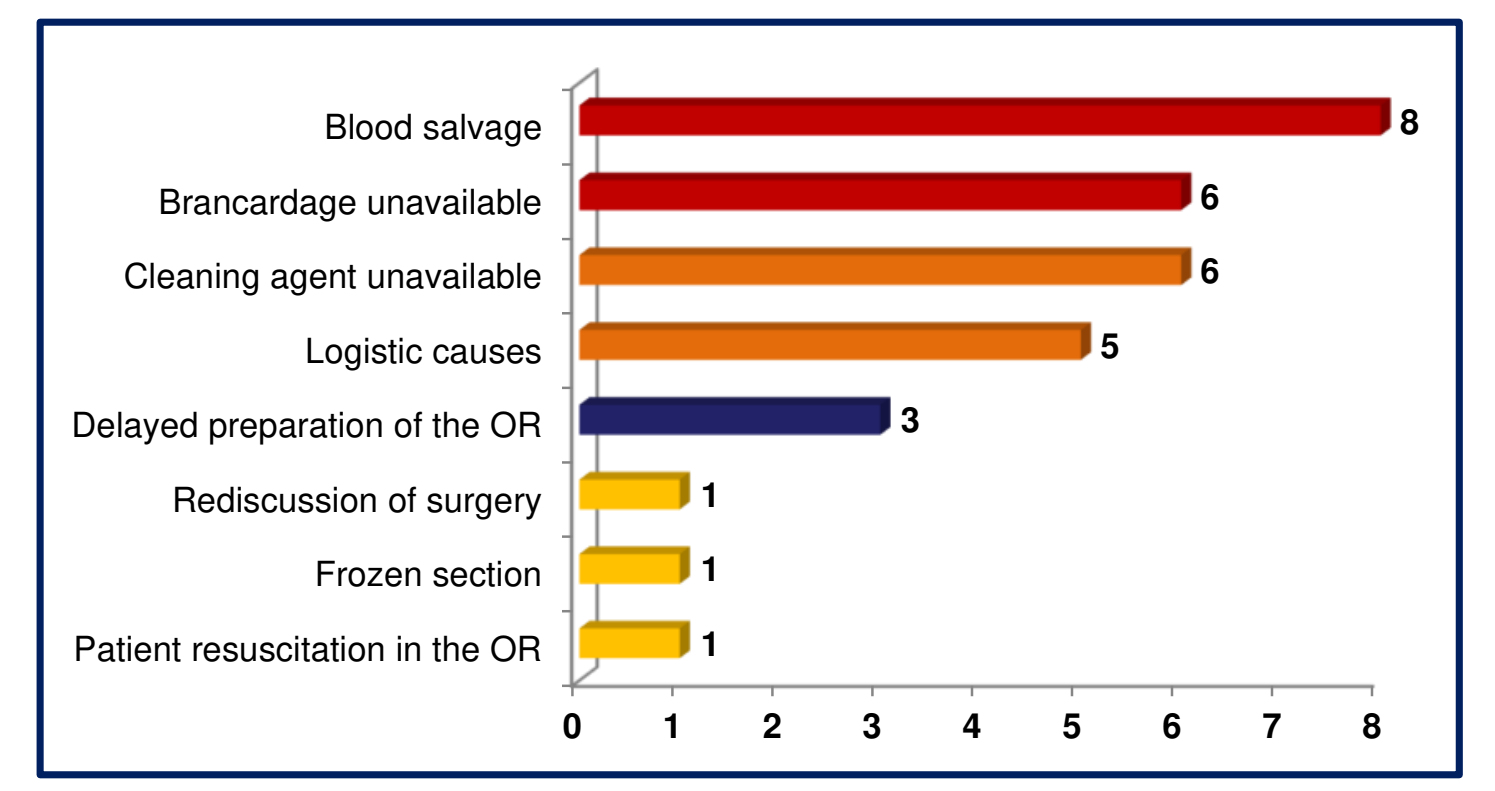

References:

1- Projet pilote : analyse du taux d'occupation des salles d'opération au moyen des données administratives. Institut canadien d'information sur la santé. Available on https://secure.cihi.ca/estore/productSeries.htm?locale=fr\&pc=PCC1284

2- Vanni Agnoletti et al. Operating room data management: improving efficiency and safety in a surgical block. BMC Surgery 2013, 13:7.

3- Patterson P. Is an $80 \%$ to $85 \%$ utilization a realistic target for Ors ? OR Manager. 1997;5: 10-3

\section{Discussion:}

The operating room activity must be the most organized possible to optimize the exploitation of available resources and to reduce the socioeconomic costs. That's why, periodic evaluations of OR performance are an essential step for any health policy aiming the good management and the improvement of health care quality.

The Canadian institute of information gave an overview of the canadian data relative to the exploitation of the OR. The RROT varied from $20 \%$ to $87 \%$ according to the hospital structures with a national average of $70 \%$ [1].

Vanni and al studied the impact of a project aiming the improvement of the OR performance in Italy. This project consists on a computerized database analyzing all stages lived by the patient during his passage by the OR and specifying in every stage the minimal and maximal authorized time. Results showed an improvement of the RROT [2].

Usually, the time of patient awakening is not considered in the RROT calculation because it is usually made in the post anesthesia care unit and not in the OR such is the case in our study.

The rate of overflow was $3.2 \% \pm 7.2$. The values held in the literature are $10 \%$ at the most and lower than $5 \%$ ideally. The rates of cancellation vary considerably from part the world and according to institutions. It can depend on the type of institutions, the type of the surgery, the population and the system of care. Also, the absence of standardized definition and the difference of methodology explains probably the wide difference of cancellation rates reported in the literature [3].

Finally, our study has some limits which must be mentioned. The short study period can not reflect the variation of the operating activity according to the time. We think that a follow-up over a period of at least one year will allow more reliable results.

In addition, our results cannot be generalized to all the rooms because every speciality has its specificities in particular as for the available resources, the workload and the interventions durations.

\section{Conclusion:}

Although the occupancy rooms rate in our hospital are acceptable, an optimized use of available resources is necessary. Corrective actions should focus primarily on delayed start-up. Periodic reassessments ideally through computerized systems are essential. 